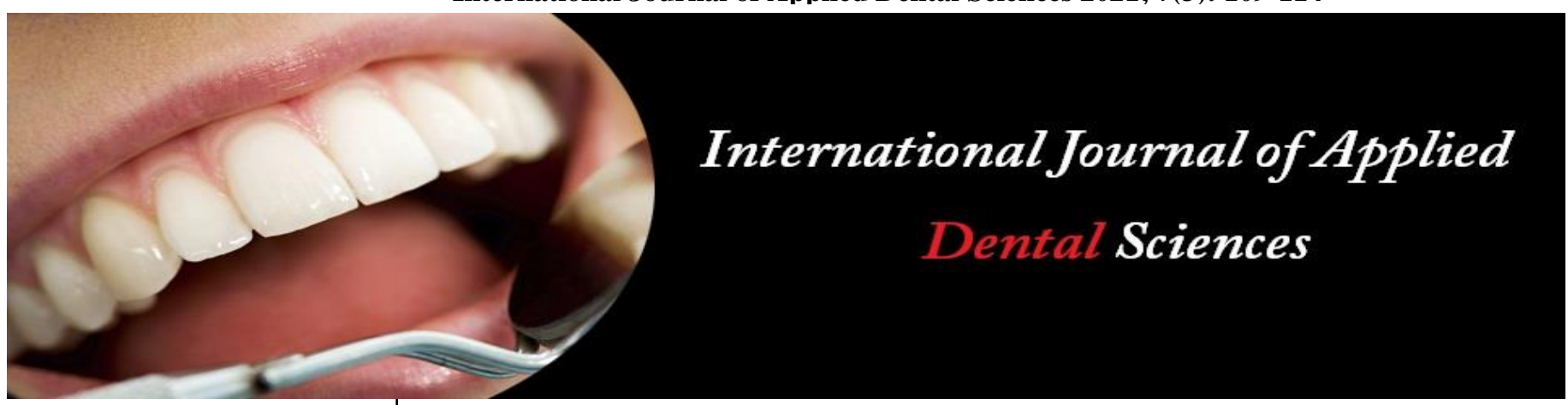

ISSN Print: 2394-7489

ISSN Online: 2394-7497

IJADS 2021; 7(3): 109-114

(C) 2021 IJADS

www.oraljournal.com

Received: 25-05-2021

Accepted: 27-06-2021

Dr. Surbhi Kapoor

B.D.S, M.D.S, Periodontonlogy

and Oral Implantology, Sri Guru

Ram Das Institute of Dental

Sciences and Research, Amritsar,

Punjab, India

Dr. Vandana

B.D.S; M.D.S, Professor and

Head, Department of

Periodontogy and Oral

Implantology, Sri Guru Ram

Das Institute of Dental Sciences

and Research, Amritsar, Punjab,

India

Dr. Supreet Kaur

B.D.S; M.D.S, Associate

Professor, Department of

Periodontology and Oral

Implantology, Sri Guru Ram

Das Institute of Dental Sciences

and Research, Amritsar, Punjab,

India

Dr. Pallavi Prashar

B.D.S; M.D.S, Periodontonlogy and Oral Implantology, Sri Guru

Ram Das Institute of Dental

Sciences and Research, Amritsar,

Punjab, India

Dr. Aradhana Sharma

Post Graduate Student,

Department of Periodontonlogy

and Oral Implantology

Sri Guru Ram Das Institute of

Dental Sciences and Research,

Amritsar, Punjab, India

Dr. Karandeep Kaur

Post Graduate Student

Department of Periodontonlogy and Oral Implantology

Sri Guru Ram Das Institute of

Dental Sciences and Research,

Amritsar, Punjab, India

Corresponding Author:

Dr. Surbhi Kapoor

B.D.S, M.D.S, Periodontonlogy

and Oral Implantology, Sri Guru

Ram Das Institute of Dental

Sciences and Research, Amritsar,

Punjab, India

\section{Gingival depigmentation: A therapeutic modality for pink esthetics: A case series}

\author{
Dr. Surbhi Kapoor, Dr. Vandana, Dr. Supreet Kaur, Dr. Pallavi Prashar, \\ Dr. Aradhana Sharma and Dr. Karandeep Kaur
}

DOI: $\underline{\text { https://doi.org/10.22271/oral.2021.v7.i3b.1289 }}$

\section{Abstract}

Hyperpigmentation is a condition where melanin is present in excess quantity which can cause significant esthetic problems. Pigmentation of gingiva is considered to be unaesthetic by patients, and it may have a psychological impact on them. This impact is aggravated in patients with "gummy smile" or excessive gingival display while smiling (high smile line). Variety of treatment modalities have been promulgated for depigmentation of gingival such as scraping, bur abrasion, partial thickness flap, cryotherapy, electrosurgery, and laser. In the present case series, techniques such as scalpel and diode laser have been tried for treatment of hyperpigmentation, which are simple, effective, and yielded good results, along with good patient satisfaction.

Keywords: hyperpigmentation, melanin, depigmentation, abrasion, cryotherapy, scalpel, laser

\section{Introduction}

An attractive smile expresses emotions of pleasure, victory, cordiality, sociability and civility. The congruence of smile is determined not only by the shape, position and colour of teeth but also by the gingival tissues ${ }^{[1]}$. Gingival health and appearance are the essential components of an attractive smile [2]. Thus, Gingival melanin pigmentation is one of the issues which determine the smile of an individual ${ }^{[1]}$.

Pigmentated lesions of the oral cavity are due to intensification of melanin production, amplified number of melanocytes or deposition of accidently introduced exogenous materials ${ }^{[3]}$.

Classification of oral pigmentation given by Greenberg et al, 2002: ${ }^{[3]}$

- Physiologic- racial

- Pathologic

- Exogenous- drug induced, tobacco chewed, smoking, heavy metals, amalgam tattoo

- Endogenous -

- Endocrine disorders such as Addisson's disease, diabetes, hyperthyroidism

- Syndrome associated such as Peutz-Jegher syndrome, Macune Albright syndrome, neurofibromatosis

- Infections such as HIV, tuberculosis, candidiasis

- chronic irritation including post traumatic and post inflammatory lesions (lichen planus, pemphigus)

- Reactive- oral melanocytic macule, oral melanoacanthoma

- Neoplastic- benign and malignant

Gingiva is the most commonly affected site for hyperpigmentation. The colour of gingiva depends on several factors: number and size of blood vessels, thickness of the epithelium, level of keratinization, quantity of pigments ${ }^{[1]}$. The most common cause of endogenous pigmentation of gingiva is melanin ${ }^{[3]}$.

Melanin is a brown coloured pigment, located in basal and suprabasal layers of gingival epithelium ${ }^{[4]}$. It is transferred to adjacent keratinocytes via membrane bound organelles called melanosomes ${ }^{[3]}$. 
Melanin pigmentation is the result of melanin granules produced by melanoblasts intertwined between epithelial cells at the basal layer of gingival epithelium ${ }^{[5]}$.

According to Greenberg et al., 2002, pigmentation induced by melanin can be black, gray, blue or brown in color. It is more prevalent in dark skinned African population and in Asians between $30 \%$ and $80 \%{ }^{[3]}$.

Although gingival melanin pigmentation does not represent a medical/pathological problem, patients with gummy smile or excessive gingival display usually complain of unesthetic "black gums" and demand cosmetic treatment ${ }^{[6]}$.

Gingival depigmentation is a periodontal plastic procedure, which aims to remove gingival hyperpigmentation by utilizing different techniques. ${ }^{7}$ The patient's demand for improved esthetics is the first and foremost indication for depigmentation. ${ }^{5}$ Different techniques present with similar results and the choice of technique must be based on experience and the patient's preferences.

Roshni \& Nandakumar in $2005{ }^{[8]}$ classified different gingival depigmentation methods as:

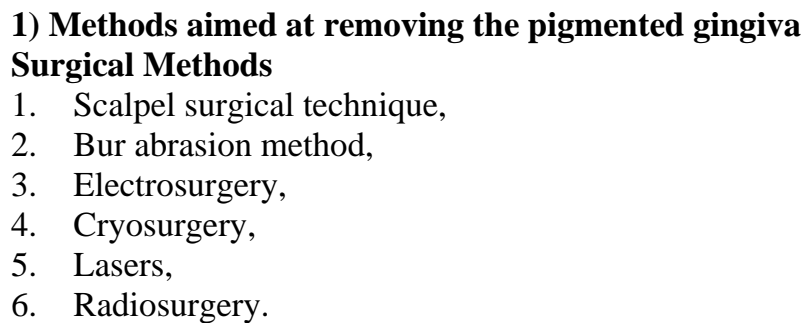

\section{2) Chemical Methods}

\section{Methods aimed at masking the pigmented gingiva}

1. Free gingival graft.

2. Acellular dermal matrix allograft.

Hence, the aim of present case series is to compare two different depigmentation techniques for eliminating melanin pigmentation in an attempt to improve esthetics and beauty of gingival tissues.

\section{Case Series}

The present case series discusses about 4 patients (two females aged 24 and 20 years and two males of age 25 and 28 years) reporting to the Department of Periodontics and Oral Implantology, SGRD Dental College, Amritsar with the common chief complaint of black coloured gums. Oral examination showed that DOPI (Dummett-Gupta Oral Pigmentation Index) score was 3 and the patients had a very high smile line that revealed pigmented gingiva from right first premolar to left first premolar in the maxillary arch and right to left canine in the mandible (Figures 1, 7, 11, 16, 19). The patients came for esthetic improvement, which could make their "black" coloured gums look better. Considering the patient's concern, surgical depigmentation procedure was planned. The treatment protocol was explained to the patients and written consents were obtained from them. Complete medical and family histories were obtained and blood investigations were carried out for ruling out any contraindications for surgery.

Scalpel surgery was planned to perform depigmentation in the maxillary arch whereas Diode Laser (PICASSO LITE, 810 $\mathrm{nm}$ ) surgery was planned for the mandibular gingiva.

Depigmentation By Scalpel (Figures 2, 8, 12, 17)

After local anesthetic infiltration (2\% Lignocaine with
1:200000 adrenaline) in the maxillary arch, a Bard parker handle with a No. 15 blade was used to remove the black pigmented layer. Pressure was applied with sterile gauze piece to control haemorrhage during the surgery. After removing the entire pigmented epithelium along with a thin connective tissue layer, care was taken to ensure that all remnants of the pigmented layer were removed. The surgical area was profusely irrigated with saline and covered with periodontal dressing in order to protect the wound from irritation.

Depigmentation by Diode Laser (Figures 4, 5, 9, 14, 20)

Under local anesthesia, depigmentation procedure was performed by Diode laser (PICASSO LITE, $810 \mathrm{~nm}$ ) at an interval of 1 week. The fiber-optic laser tip with a diameter of $400 \mu \mathrm{m}$ was used in continuous mode and kept in contact with the pigmented area at power setting of $1.3 \mathrm{~W}$. Depigmentation was performed in a horizontal direction, using the laser tip in contact mode on the pigmented part of the gingiva and parallel to the surfaces of root. Care was taken to avoid overheating, and the depigmented area was wiped with gauze soaked in saline. After the procedure, no periodontal pack was applied. Patients were instructed to avoid smoking and hot, acidic, and spicy foods that can interfere with the healing process and cause patient discomfort.

Following depigmentation, patients were recalled at weeks 1, 4, and 12 postoperatively for clinical evaluation and repigmentation rate. The wounds healed completely in 1 week (Figures 3, 6, 10, 13, 15, 18, 21). Re-epithelisation was complete by 1 month and gingiva appeared healthy and generalized pink in colour without pigmentation at the end of 3 months.

In all the four cases, patients were post prescribed antibiotics (Amoxicillin $500 \mathrm{mg}$ twice daily for five day) and analgesics (Ibuprofen with paracetamol, twice daily for three days). The patients were also advised to use $0.12 \%$ chlorhexidine mouth rinses twice daily for one week post operatively.

None of the patients reported with postoperative complications such as pain, swelling, bleeding, infection, necrosis etc and were satisfied with the treatment outcomes.

\section{Discussion}

Gingiva is the most common area of the intraoral tissues which is pigmented as compared to other tissues. Melanin is the most essential pigment that colours the gingival tissues. It appears as soon as three hours after birth in the oral tissues and in some cases, it is the only sign of pigmentation on the body ${ }^{[1]}$. The gingival pigmentation is seen in all races and age groups, and there is no gender predilection ${ }^{[7]}$. The severity and distribution of pigmentation of the mucosa varies, not only between races but also between different individuals of the same race and within different areas of the samemouth ${ }^{[9]}$. Demand for esthetic treatment of gingival hyperpigmentation is widespread and various modalities ranging from scalpel to laser have been used for this purpose. However, removal of gingival melanin pigmentation should be performed with caution and the adjacent teeth should be protected, since inappropriate treatment modality may cause gingival recession, damage to underlying periosteum and bone, delayed wound healing, as well as loss of enamel ${ }^{[7]}$.

In the present case series, Scalpel and Diode Laser technique have been used for gingival depigmentation and patients were scored on the basis of the following criteria: 


\section{Dummett-Gupta Oral Pigmentation Index (DOPI):} (Dummett 1971) ${ }^{[10]}$

1. No clinical pigmentation (pink gingiva)

2. Mild clinical pigmentation (mild light brown color)

3. Moderate clinical pigmentation (medium brown or mixed pink and brown)

4. Heavy clinical pigmentation (deep brown or bluish black).

The smile line classification (Liebart and Deruelle 2004) ${ }^{[11]}$

Class 1: Very high smile line - more than $2 \mathrm{~mm}$ of the marginal gingiva visible.

Class 2: High smile line - between 0 and $2 \mathrm{~mm}$ of the marginal gingiva visible.

Class 3: Average smile line - only gingival embrasures visible.

Class 4: Low smile line - gingival embrasures and cementoenamel junction not visible.

One of the first and still popular techniques employed is the surgical removal of undesirable pigmentation using scalpels. This procedure essentially involves surgical removal of entire gingival epithelium along with a layer of underlying connective tissue, thereby allowing the denuded connective tissue to heal by secondary intention. The new epithelium that forms is devoid of melanin pigments ${ }^{[5]}$. Also, this modality is the most cost effective and popular method as compared to other techniques, which require more advanced and costly armamentarium ${ }^{[1]}$. According to Almas and Sadiq (2002) ${ }^{[12]}$, the scalpel wounds heal faster than those in other techniques. In this case series, the scalpel method gave satisfactory results from both clinical and patient's point of view. However, although the technique is simple and versatile, it causes unpleasant bleeding during and after the surgery, and it is mandatory to cover the surgical site with periodontal dressing for a period of $7-10$ days ${ }^{[5]}$.

So, to avoid unnecessary bleeding, another effective treatment modality employed in the present case series is the depigmentation by diode laser. This technique is based on the mechanism of transformation of radiation energy into ablation energy that results in cellular rupture and vaporization with minimal heating of the surrounding tissues ${ }^{[13]}$. Recently, laser ablation has been recognized as one of the most effective, comfortable and reliable techniques for gingival depigmentation ${ }^{[6]}$.

Sharon et al, $2000{ }^{[14]}$ found $\mathrm{CO}_{2}$ laser to be effective in eliminating the pigmented areas in all treated tissues with no recurrence of melanin detected in either the oral mucosa or gingival tissues ${ }^{[3]}$.

Laser beam produces bloodless field of surgery, causes minimal damage to the periosteum and underlying bone, and the treated gingiva and mucosa do not need any periodontal dressing. Also, laser therapy has advantages of easy handling, reduced treatment duration, hemostasis, decontamination and sterilization effects ${ }^{[2]}$. Laser beam also destroys the epithelial cells including those at the basal layer, and hence reduces the rate of repigmentation. But this approach needs expensive and sophisticated equipments, which makes the treatment very expensive ${ }^{[13]}$.
Case 1

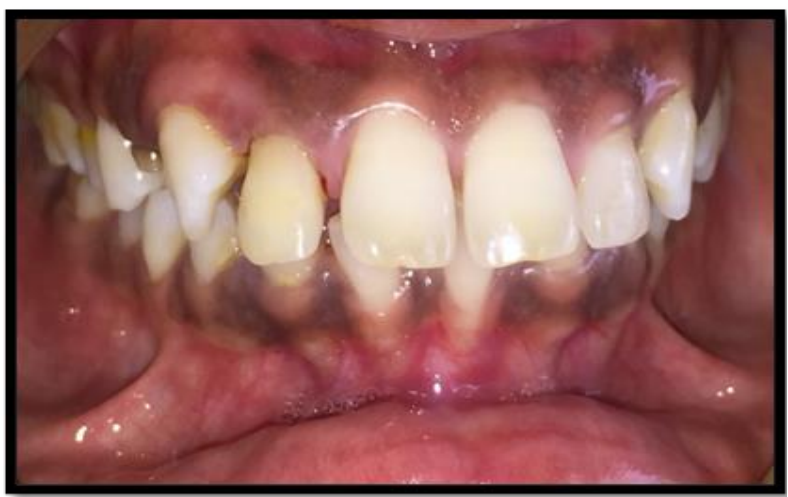

Fig 1: Pre-Operative View

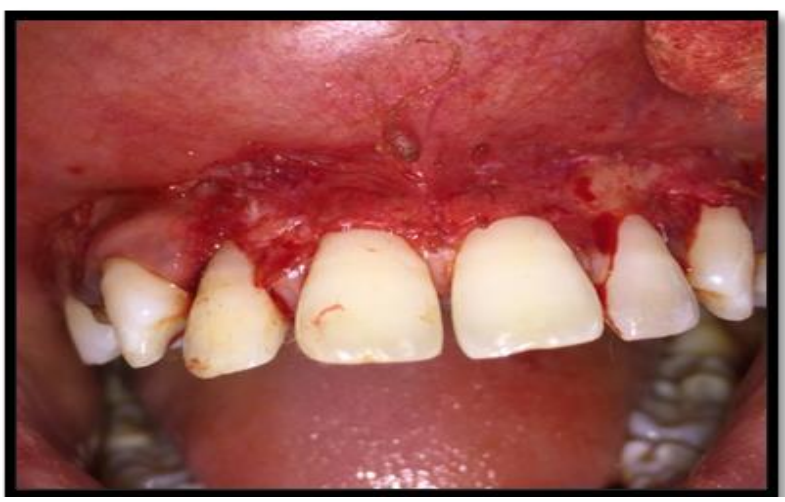

Fig 2: De-Epithelialization With Scalpel

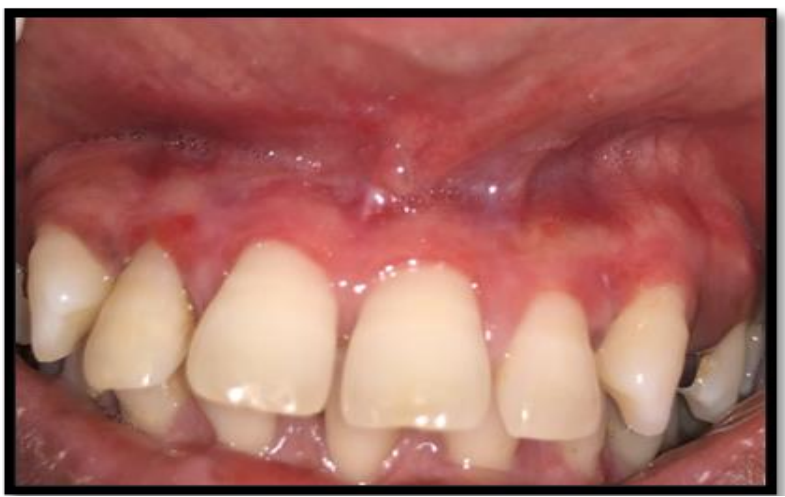

Fig 3: Healing After 1 Week

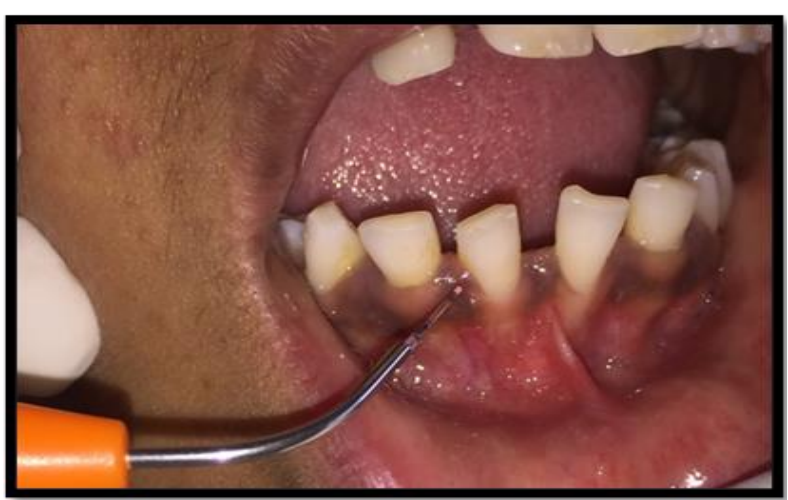

Fig 4: De-Epithelialization With Diode Laser 


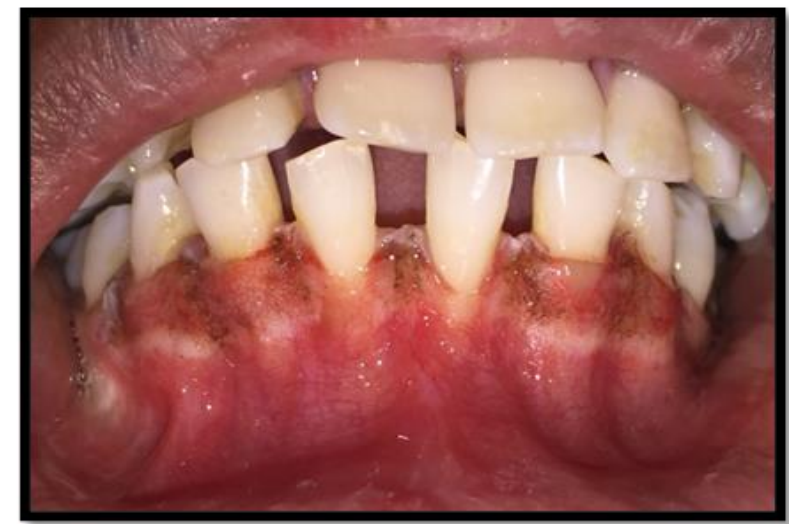

Fig 5: After Surgery

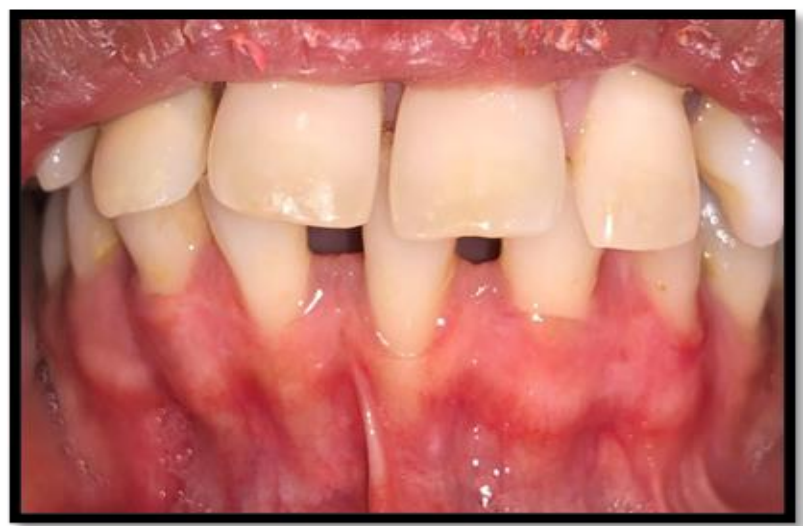

Fig 6: Healing After 1 Week

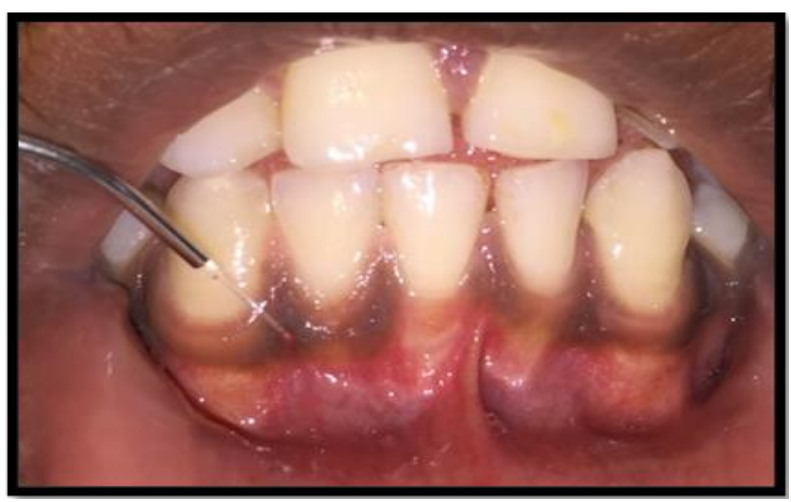

Fig 9: De-Epithelialization With Diode Laser

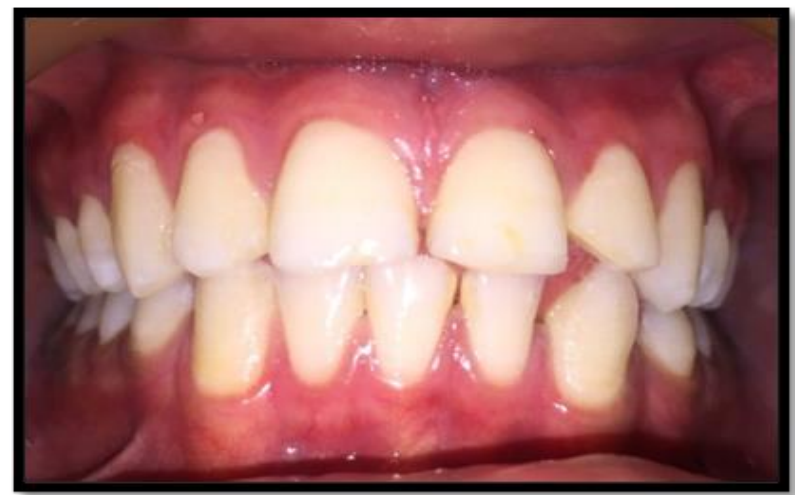

Fig 10: Healing After 1 Week

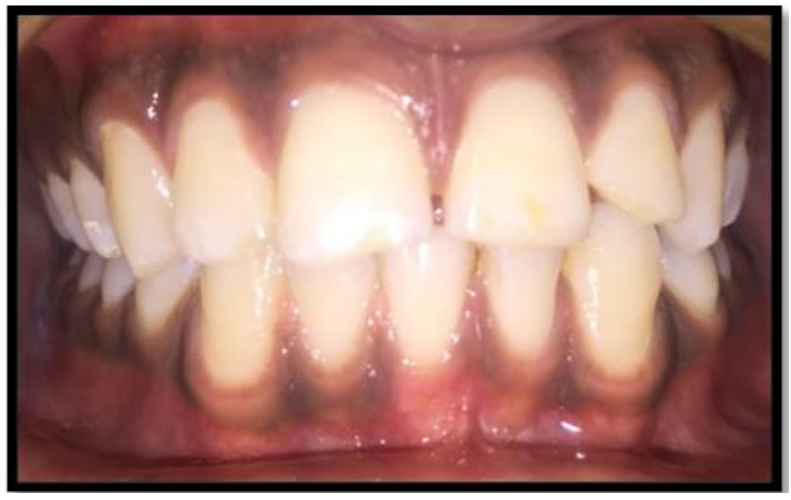

Fig 7: Pre-Operative View

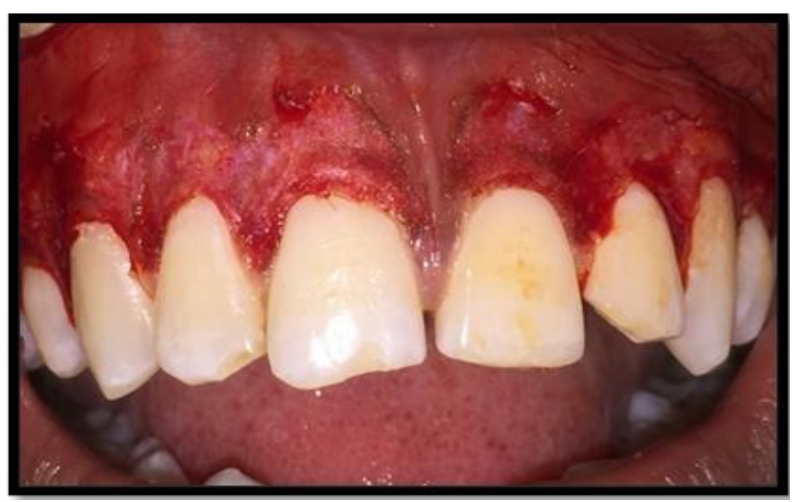

Fig 8: De-Epithelialization With Scalpel

Case 2

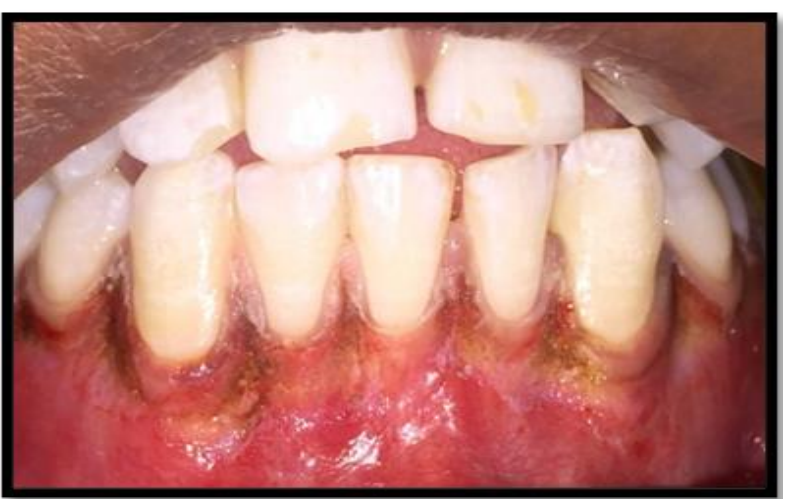

$+$ 
Case 3

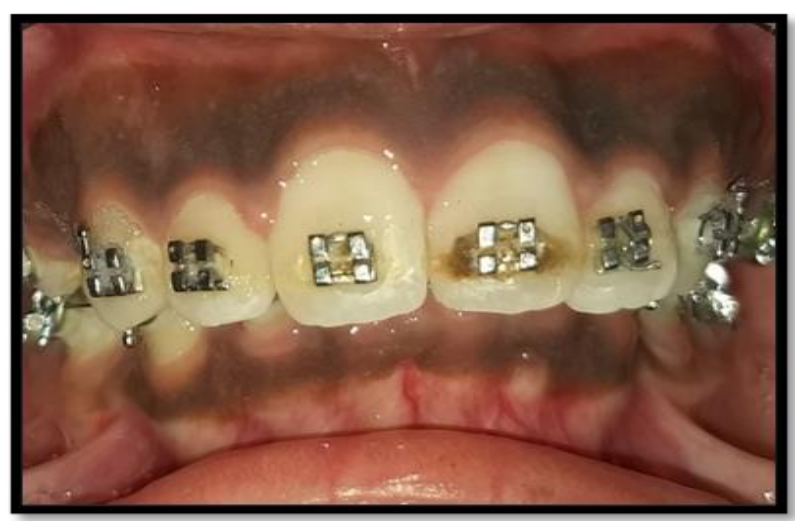

Fig 11: Pre-Operative View

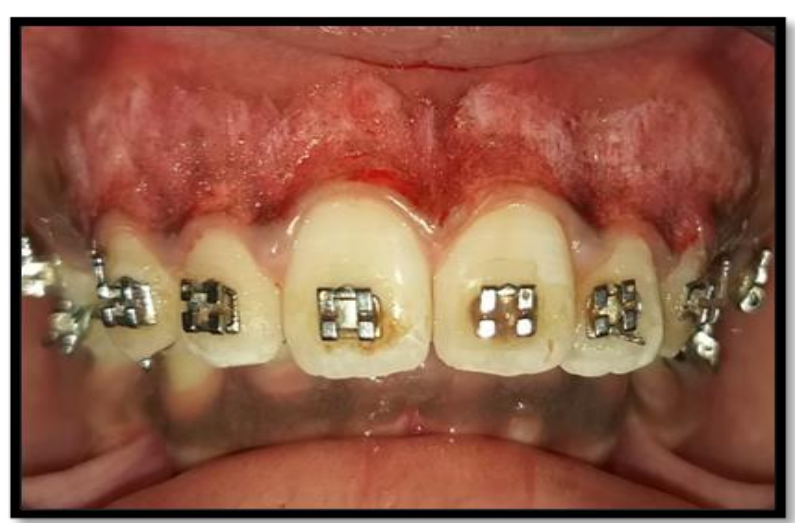

Fig 12: De-Epithelialization With Scalpel

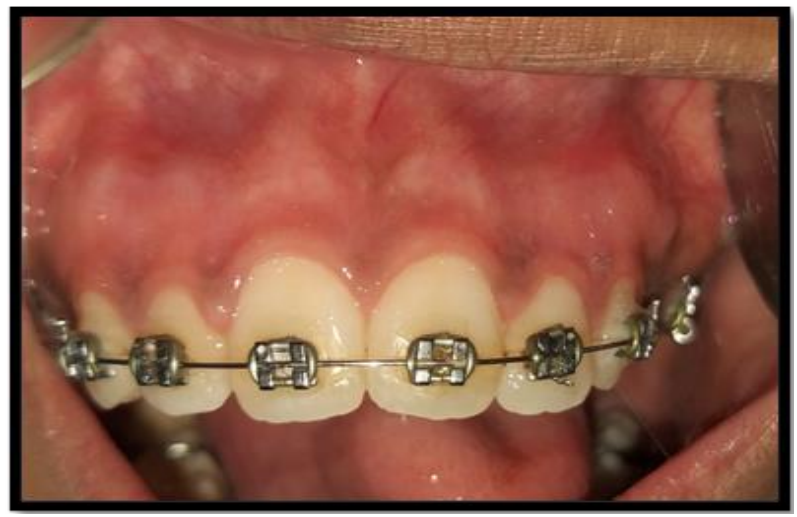

Fig 13: Healing After 1 Week

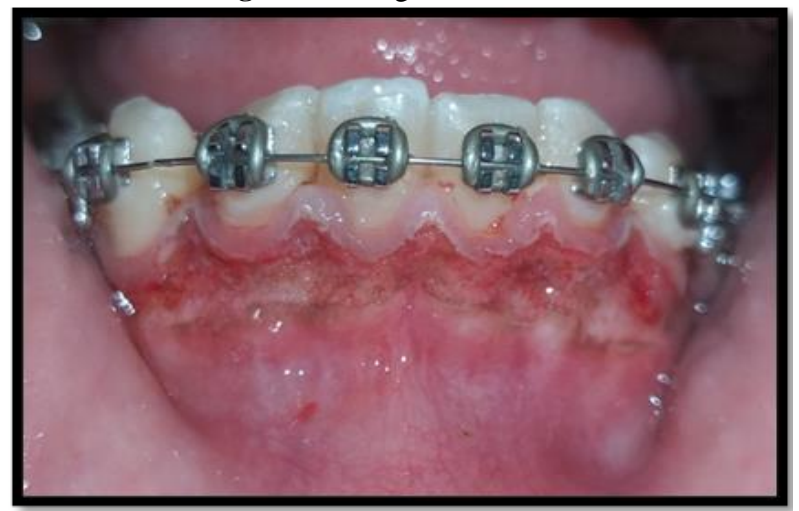

Fig 14: De-Epithelialization With Diode Laser

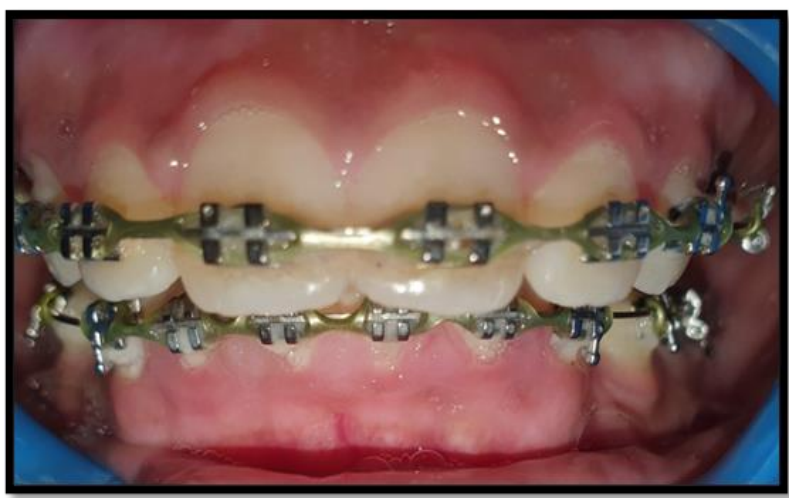

Fig 15: Healing After 1 Week

Case 4

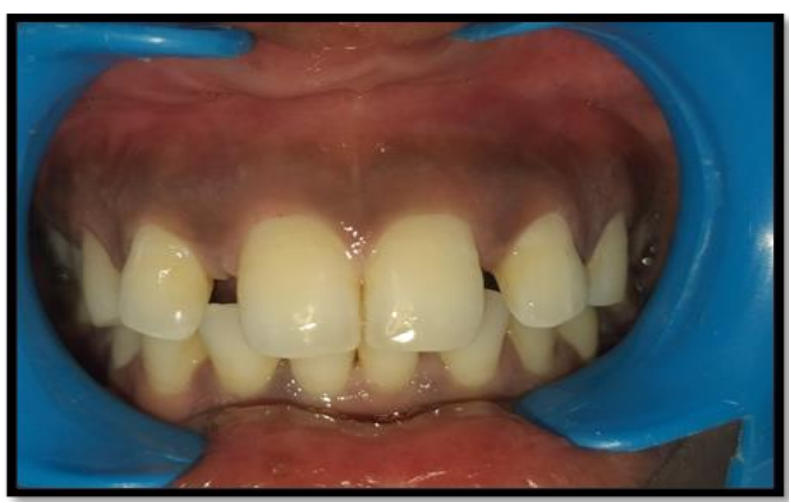

Fig 16: Pre-Operative View

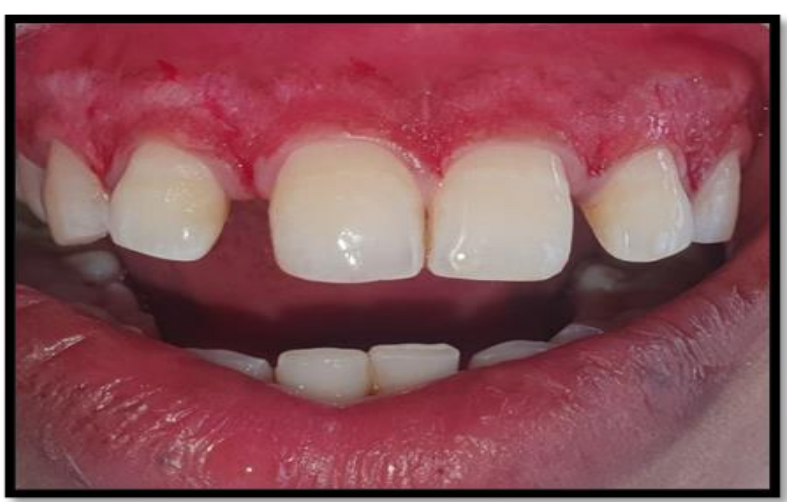

Fig 17: De-Epithelialization With Scalpel

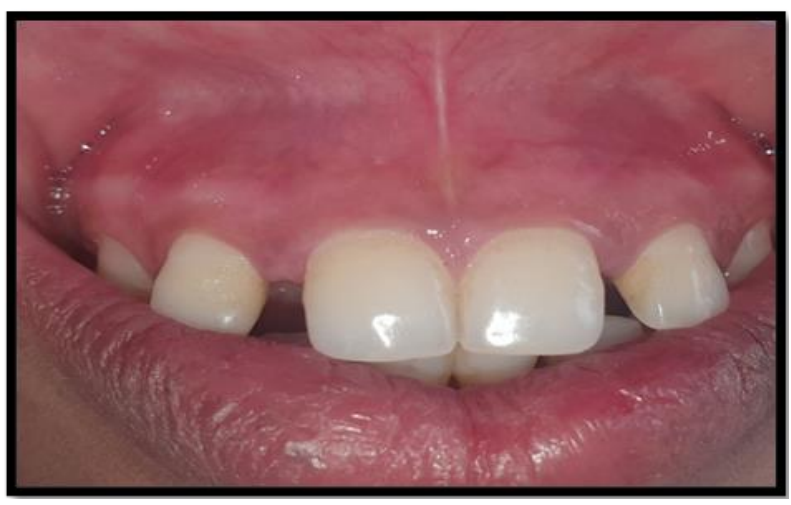

Fig 18: Healing After 1 Week 


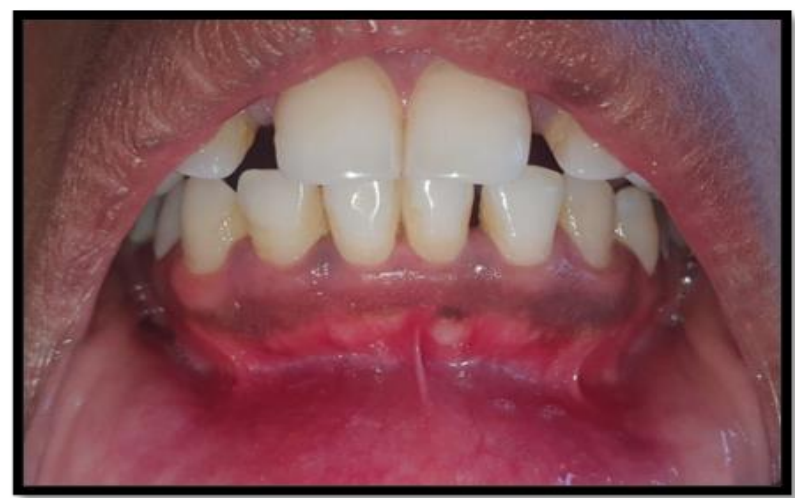

Fig 19: Pre-Operative View

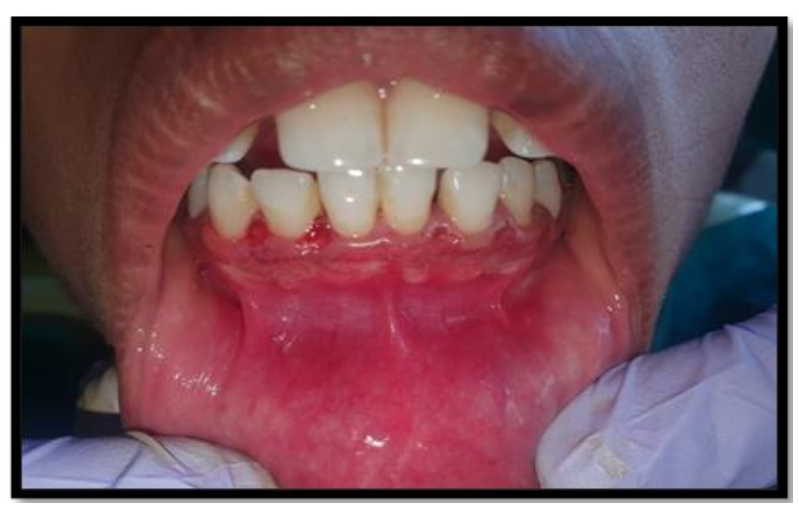

Fig 20: De-Epithelialization With Diode Laser

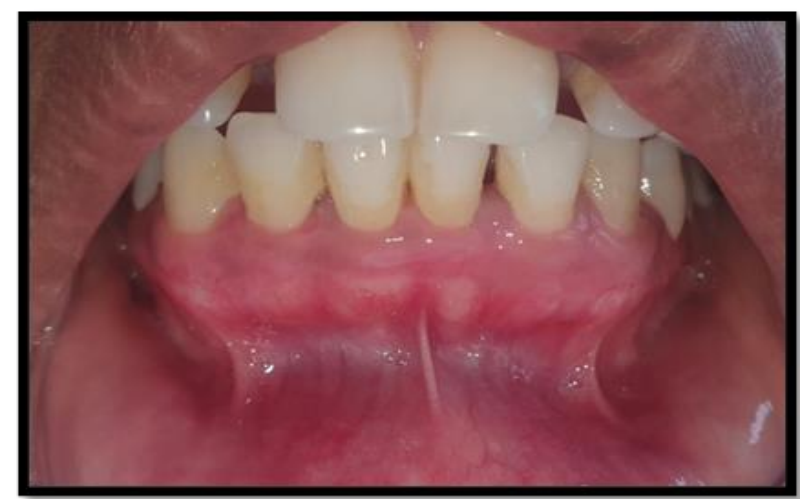

Fig 21: Healing After 1 Week

\section{Conclusion}

Gingival melanin pigmentation varies depending upon whether it is physiological or pathological as well as on the basis of location and colour. The growing concern for esthetics requires the removal of unsightly pigmented gingival areas in order to create a pleasant and confident smile, which eventually may alter the personality of an individual. The most important factor in determining the treatment modality for pigmentation is the type of pigmentation, patient acceptance of treatment procedure, its prevalence and its esthetic importance depending on the skin complexion of the patient. The methods discussed here produced desired results, and above all, the patients were satisfied with the treatment outcome, which is the ultimate goal of any therapy that is carried out.

\section{References}

1. Nema A, Patil SS, Budhiraja H, Sikarwaar N, Sengar MS. Gingival depigmentation: Aesthetic approach- Case report and mini review. Int J Adv Res 2017;5(6):874-81.

2. Srivastava S, Srivastava T, Diwedi T, Yadav P. Gingival melanin depigmentation: A review and case report. J Orofac Res 2014;4(1):50-4.

3. Mishra M, Niswade G, Chandok J, Bathiya A. Depigmentation: A review and case report. International Journal of Current Research 2017;9(6):52571-5.

4. Elemek E. Gingival melanin depigmentation by $810 \mathrm{~nm}$ diode laser. Eur J Dent 2018;12:149-52.

5. Patil KP, Joshi V, Waghmode V, Kanakdande V. Gingival depigmentation: A split mouth comparative study between scalpeland cryosurgery. Contemp Clin Dent 2015;6:S97-10.

6. El Shenawy HM, Nasry SA, Zaky AA, Quriba MAA. Treatment of gingival hyperpigmentation by diode laser for esthetical purposes. OA Maced $\mathbf{J}$ Med Sci 2015;3(3):447-54.

7. Alqahtani SM. Management of gingival hyperpigmentation by surgical abrasion: A case report. Int J Med Dent Case Rep 2015:1-3

8. Roshna T, Nandakumar K. Anterior esthetic gingival depigmentation and crown lengthening: report of a case. $\mathbf{J}$ contemp dent pract 2005;(6)3:139-147.

9. Thakur K, Sharma S, Basith A, Biir MSM. Gingival Depigmentation - A Case Report. J Adv Med Dent Scie Res 2018;6(4):33-5.

10. Dummet CO, Barens G. Oromucosal pigmentation: An updatedliterary review. J Periodontol 1971;42:726-36.

11. Liebart ME, Deruelle CF, Santini A, Dillier FL, Corti VM. Smile line andperiodontium visibility. Perio 2004;1:17-25.

12. Almas K, Sadiq W. Surgical Treatment of MelaninPigmented Gingiva: An Esthetic Approach. Indian J Dent Res 2002;13:70-3.

13. Thangavelu A, Elavarasu S, Jayapalan P. Pink esthetics in periodontics - Gingival depigmentation: A case series.J Pharm Bioall Sci 2012;4:186-90.

14. Sharon E, Azaz B. Vaporisation of melanin in oral tisues andskin with a CO2 laser: A canine study. J Oral Maxillofac Surg 2000;58:1387-1393. 